\title{
Optimal Operation of Micro-grids Considering the Uncertainties of Demand and Renewable Energy Resources Generation
}

\author{
Malek Jasemia ${ }^{*}$, Farid Adabib , Babak Mozafaric , Samira Salahi ${ }^{\mathrm{d}}$ \\ a Young Researchers and Elite Club, Rasht Branch, Islamic Azad University, Rasht, Iran. \\ ${ }^{b}$ Department of Electrical Engineering, Sanandaj Branch, Islamic Azad University, Sanandaj, Iran. \\ ${ }^{c}$ Department of Electrical Engineering, Tehran Science and Research Branch, Islamic Azad University, Tehran, Iran. \\ d Young Researchers and Elite Club, Khorramabad Branch, Islamic Azad University, Khorramabad, Iran.
}

\begin{abstract}
Nowadays, due to technical and economic reasons, the distributed generation (DG) units are widely connected to the low and medium voltage network and created a new structure called micro-grid. Renewable energies (especially wind and solar) based DGs are one of the most important generations units among DG units. Because of stochastic behavior of these resources, the optimum and safe management and operation of micro-grids has become one of the research priorities for researchers. So, in this study, the optimal operation of a typical micro-grid is investigated in order to maximize the penetration of renewable energy sources with the lowest operation cost with respect to the limitations for the load supply and the distributed generation resources. The understudy micro-grid consists of diesel generator, battery, wind turbines and photovoltaic panels. The objective function comprises of fuel cost, start-up cost, spinning reserve cost, power purchasing cost from the upstream grid and the sales revenue of the power to the upstream grid. In this paper, the uncertainties of demand, wind speed and solar radiation are considered and the optimization will be made by using the GAMS software and mixed integer planning method (MIP).
\end{abstract}

Keywords: Micro-grid, Optimal operation, Renewable energy resources, Uncertainty, DG

Article History: Received May 21, 2016; Received in revised form July 11, 2016; Accepted October 15, 2016; Available online How to Cite This Article: Jasemi, M., Adabi, F., Mozafari, B., and Salahi, S. (2016) Optimal Operation of Micro-grids Considering the Uncertainties of Demand and Renewable Energy Resources Generation, Int. Journal of Renewable Energy Development, 5(3),233-248.

http://dx.doi.org/10.14710/ijred.5.3.233-248

\section{Introduction}

During recent decades, due to increased electricity demand, security of supply, environmental concerns (climate change, nature preservation, pollution), increased sustainability, difficulty in building new large generation and transmission/infrastructures. Distributed generation (DG) has become an interesting alternative for power generation. In this way, generating units are being connected to the distribution network rather than the transmission network and located at or near where the electricity is being used.

DG refers to the generation of electricity by smallscale facilities which are divided into renewable energy and fossil fuel based units. Due to different reasons such as, fossil fuel price variations and limitation of these resources, environmental problem of renewable energy based DG units especially wind turbine (WT) and photovoltaic (PV) system are developed increasingly.

The integration of DG within existing networks introduced micro-grid concept. According to CIGRÉ C6.22 definitions, "Micro-grids are electricity distribution systems containing loads and distributed energy resources, (such as distributed generators, storage devices, or controllable loads) that can be operated in a controlled, coordinated way either while connected to the main power network or while islanded".

Emergence of micro-grid concept may cause particular problems in the control of power flow, power 
Citation: Jasemi, M., Adabi, F., Mozafari, B., Salahi, S. (2016). Optimal Operation of Micro-grids Considering the Uncertainties of Demand and Renewable Energy Resources Generation. Int. Journal of Renewable Energy Development, 5(3), 233-248, doi: 10.14710/ijred.5.3.233-248

$\mathrm{P}$ a g e $\mid 234$

quality and protection. Indeed, increasing DG units at the LV network can significantly affect the electrical power grids operation and planning and lead to the complexity of distribution network control, protection and maintenance. In addition, in order to maximize the benefits of available resources in a micro-grid, an optimal schedule of power generation is needed.

Because of above mentioned reasons, in recent years a great attention has been dedicated to optimal operation problem of micro-grids and it became a research priority among researchers all over the world (Salahi et al. 2016; Allali et al. 2015; Bahramara et al. 2015; Alharbi et al. 2015; Elsied et al. 2016; Dai et al. 2013; Hatziargyriou et al. 2007; Niknam et al. 2012; Kanchev et al. 2011; Baziar et al. 2013; Chen et al. 2011; Peik-Herfeh et al. 2013).

In the current study considering the uncertainties of load and renewable energy resources (wind speed and solar radiation) optimal day-ahead unit commitment problem for a micro-grid consisting of diesel generator, battery, wind turbines and photovoltaic panels will be presented and results will be compared with the case in which uncertainties are not considered. In order to considering the uncertainties, both additional reserve requirement technique and multi-scenario stochastic models are used and compared.

This paper is organized as follows: The second section presents some studies on this filed and their results. The third section shows the mathematical formulas for the system model and day-ahead unit commitment problem of micro-grids. In the fourth section, the parameters in the understudy micro-grid have been given, and the fifth section represents the results for the optimal operation of the given micro-grid. In this section, also, the uncertainties and spinning reserve effects on the micro-grid costs and operations are evaluated and finally, conclusion will be done in the sixth section.

\section{Literature Review}

Lagorse et al. (2010) have introduced a typical MultiAgent Systems (MAS) based solutions for energy management of a hybrid micro-grid. The results show that this method is perfectly valid and can solve the most problems with central Energy Management System (EMS). Hanane Dagdougui et al. (2012) have presented a dynamic model for finding a renewable energy-based optimal combination in order to meet the power electrical and thermal demands of a "Green" building. The optimization problem has been solved based on a proposed Model Predictive Control (MPC) algorithm. The proposed technique has been tested for the Capo Vado site in Liguria, Italy with and without energy storage system while generation system comprises of wind turbines, photovoltaic panels, biomass system and flat plate collector... The results show that 55\%, 18\%,
$15 \%$ and $12 \%$ of demands have been met by wind turbine, PV modules, storage system and upstream grid, respectively. (Yen-Haw Chen et al. 2012) have suggested an optimal energy management model to maximize profits of a micro-grid including storage system, wind turbine and photovoltaic power generation systems in Taiwan and results indicate that a high-capacity battery needs more investment and the larger accessories installation is not cost-effective. (Taher Niknam et al. 2012) are proposed a probabilistic approach for the energy and operation management (EOM) of micro-grids considering uncertainties. The proposed framework is based on $2 \mathrm{~m}$ point estimate method and a self-adaptive optimization algorithm based on the gravitational search algorithm (GSA). In this paper uncertainty of demand, market prices and the available electrical power of wind farms and photovoltaic systems are considered. Selfadaptive mutation technique is offered to enhance the convergence characteristics of the original GSA and avoid being entrapped into local optimum. The effectiveness of the proposed method is confirmed on a typical grid connected micro-grid. The simulation results show that the proposed optimization method can find robust, reliable and high quality solutions in a satisfactory simulation time for energy management problems and probabilistic approach can provide a more efficient utilization of the renewable energy sources. (Osama Mohammed et al. 2013) are proposed an effective algorithm for optimizing distribution system operation in a smart grid, considering lower cost and higher stability as objectives. Various case studies are inspected to verify the validity of the proposed algorithm and system behavior analyzed under varying conditions. (Abedi et al. 2012) are presented a new method for optimal power management strategy (PMS) of hybrid energy systems including various generation system including wind turbines, PV panels, fuel cells, electrolyzers, hydrogen tanks, batteries, and diesel generator. Differential evolution algorithm (DEA) accompanied with fuzzy technique with the aim of minimizing the overall cost of the system, unmet load, and fuel emission considering the uncertainties associated with renewable energy sources is used to handle the mixed-integer nonlinear multi-objective optimization problem. In order to have efficient power utilization from RES, the optimum monthly tilt angles of photovoltaic panels and the optimum tower height for wind turbines are calculated. Comparative results show the effectiveness and capability of the proposed method for hybrid energy systems. In (Motevasel et al. 202) an IEMS (intelligent energy management system) is proposed for optimal operation of a CHP-based microgrid over a 24-hour time interval. In this paper, a smart energy storage system is presented which consists of electrical and thermal storage systems and efficient Modified Bacterial Foraging Optimization (MBFO) algorithm is proposed to solve the problem. Proposed method is tested on a micro-grid which consists of 
renewable energy sources, CHP unit, ESS and thermal and electrical loads. The results show the accuracy of MBFO as compared to some other optimization algorithms, as the IEMS can evaluate the optimal generation of renewable energy sources, boiler and electrical and thermal storage devices with minimum operating and environmental pollution costs.

\section{Model formulation}

\subsection{Modeling of the uncertainty}

The main purpose of solving the day-ahead unit commitment problem is to schedule the power generation in a system in order to supply the forecasted demand and the reserve requirement at a minimum operating cost. However, without considering uncertainties, the obtained solution might not be optimal or even feasible. Therefore, it is highly important to consider the uncertainties. There are two main approaches presented in the literature to handle uncertainties: additional reserve requirement and multiscenario stochastic models (Alabedin 2012). In this paper, both methods have been used for modeling uncertainties.

\subsubsection{Formulation of the multi-scenario stochastic model}

From (Alabedin 2012), the forecasted values of a stochastic phenomenon consist of two main components that are added together: the expected value and the forecasting error.

$$
X_{f}(t)=X_{e}(t)+e_{X}(t)
$$

Where $X_{-} f(t), X_{-} e(t)$ and $e_{-} X(t)$ are the forecasted value, the expected value and the forecasting error at time $t$ respectively (Alabedin 2012).

The discrete sets of the load $\delta_{D}$, wind $\delta_{W}$, and solar power $\delta_{p V}$ forecasting errors are described as:

$$
\begin{aligned}
& \delta_{D}=\left\{\left(e_{D}^{1}, \rho_{D}^{1}\right),\left(e_{D}^{2}, \rho_{D}^{2}\right), \ldots\left(e_{D}^{n}, \rho_{D}^{n}\right)\right\} \\
& \delta_{W}=\left\{\left(e_{W}^{1}, \rho_{W}^{1}\right),\left(e_{W}^{2}, \rho_{W}^{2}\right), \ldots\left(e_{W}^{n}, \rho_{W}^{n}\right)\right\} \\
& \delta_{p V}=\left\{\left(e_{p V}^{1}, \rho_{p V}^{1}\right),\left(e_{p V}^{2}, \rho_{p V}^{2}\right), \ldots\left(e_{p V}^{n}, \rho_{p V}^{n}\right)\right\}
\end{aligned}
$$

Where $\mathrm{e}_{\mathrm{D}}^{\mathrm{i}}$ is the error of the $\mathrm{i}^{\text {th }}$ state in the probability distribution function (PDF) of load forecasting error, $\rho_{D}^{i}$ is the corresponding probability, and $\mathrm{n}$ is the total number of states in the discrete set (Alabedin 2012). The discrete sets of wind and solar power forecasting errors are defined similarly. The states' probabilities are subject to:

$$
\sum_{i=1}^{n} \rho_{D}^{i}=\sum_{i=1}^{m} \rho_{W}^{i}=\sum_{i=1}^{q} \rho_{p V}^{i}=1
$$

The discrete sets in Equations (2), (3), and (4) are used to create a set of scenarios that represent the possible deviations from the load, wind power, and solar power forecasted values. Using a two-stage scenario tree that branches only at the first time period and ignores the effect of time at the remaining periods, a set of scenarios is created. The total number of scenarios equals to the product of the number of states in each discrete set (Alabedin, 2012).Each scenario has a probability $\rho_{s}$ that is equal to the product of the probabilities of the states' corresponding to that scenario:

$$
\begin{aligned}
& \sum_{s=1}^{S} \rho_{s}=\sum_{s=1}^{S} \rho_{D}^{s} \rho_{W}^{s} \rho_{p V}^{s}=1 \\
& S=n \times m \times q
\end{aligned}
$$

Where $\mathrm{S}$ is the total number of scenarios. The created scenarios and their corresponding probabilities are used to formulate the unit commitment problem as a multiscenario stochastic model. An optimal solution that satisfies all the constraints under any scenario should be found (Alabedin 2012).

\subsection{Problem formulation}

In this section the problem formulation presents for the unit commitment problem in a micro-grid. The presented model considers additional reserve requirement to provide the uncertainties of load and generating power of renewable source. Also, a wide range of uncertainties have been considered with respect to some possible scenarios and finally, they were solved through the Mixed Integer Programing (MIP).

\subsubsection{Objective function}

General purpose of the unit commitment problem to minimize the operational costs which are include the start-up cost, the fuel cost of diesel generators, the reserve cost, the cost of the power imported from the upstream grid and the revenue from sold surplus power to the upstream grid. To do so, the objective function presented as follows:

$$
\begin{aligned}
\min Z= & \sum_{s=1}^{S} \rho_{s}\left[\sum_{t=1}^{T} \sum_{j=1}^{J} \sum_{s=1}^{S}\left(C_{j}\left(P_{j t s}\right)+S U_{j t s}\right)+\right. \\
& \sum_{t=1}^{T} \sum_{s=1}^{S}\left(S R_{m g, t s} \times C_{r}\right)+ \\
& \sum_{t=1}^{T} \sum_{s=1}^{S}\left(P_{\text {insert }, t s} \times C_{\text {upstream }}\right)- \\
& \left.\sum_{t=1}^{T} \sum_{s=1}^{S}\left(P_{\text {out }, t s} \times C_{\text {upstream }}\right)\right]
\end{aligned}
$$


Where $C_{j}\left(P_{j t s}\right)$ is the fuel cost of the jth unit that supplies power $P_{j t s}$ at time t, and, $S U_{j t s}$ is the start-up cost of jth unit at time t. The fuel cost is a nonlinear function of the power output that calculates as follows:

$C_{j}\left(P_{j t s}\right)=a_{j} \alpha_{j t s}+b_{j} P_{j t s}+c_{j} P_{j t s}^{2} \quad, \quad \forall j$

Where $a_{j}, b_{j}, c_{j}$ are the cost coefficients of unit $\mathrm{j}$. Equation 9 can be linearized as follow:

$C_{j}\left(P_{j t s}\right)=a_{j} \alpha_{j t s}+b_{j} P_{j t s} \quad, \quad \forall j$

Also, the start-up cost $S U_{j t s}$ is modeled as total turn on shut-down costs.

$S U_{j t s}=S T C_{j} \times \beta_{j t s}+S D C_{j} \times \gamma_{j t s}$

\subsubsection{Constraints}

The technical constraints considered in this paper are as follows:

\subsubsection{Diesel generators' constraints}

- Output power limits:

$P_{j}^{\min } \leq P_{j t s} \leq P_{j}^{\max }, \forall j, t, s$

- Ramp rate limits:

$P_{j(t-1) s}-R R_{j} \leq P_{j t s} \leq P_{j(t-1) s}+R R_{j}, \forall j, t, s$

- Minimum-up and down time limits:

$$
\begin{aligned}
& \sum_{l=1}^{M U T} \alpha_{j(t+l) s} \geq M U T_{j} \\
& \sum_{l=1}^{M D T} \alpha_{j(t+l) s}-1 \leq M D T_{j}
\end{aligned}
$$

- Logic constraint:

$$
\begin{aligned}
& \alpha_{j t s}-\alpha_{j(t-1) s} \leq \beta_{j t s} \\
& \alpha_{j(t-1) s}-\alpha_{j t s} \leq \gamma_{j t s} \\
& \alpha_{j t s}-\alpha_{j(t-1) s}=\beta_{j t s}-\gamma_{j t s}
\end{aligned}
$$

\subsubsection{System constraints}

- Power balance:

$$
\begin{gathered}
\sum_{j=1}^{J} P_{j t s}+W_{t s}\left(1+\mathrm{e}_{W}^{i}\right)+P V_{t s}\left(1+\mathrm{e}_{P V}^{i}\right)+ \\
P_{\text {insert }, t s}+P_{\text {discharg } e, t s}=D_{t}\left(1+\mathrm{e}_{D}^{i}\right)+ \\
P_{\text {out }, t s}+P_{\text {charg } e, t s} \quad, \forall j, t, s
\end{gathered}
$$

- Upstream grid power limits:

$O \leq P_{\text {insert,ts }} \leq P_{\text {upstream }}^{\max }, \forall t, s$

$O \leq P_{\text {out } t \text { ts }} \leq P_{\text {upstream }}^{\max } \quad, \forall t, s$

- Spinning reserve limits:

$$
\begin{aligned}
& S R_{j t s}=\left(\alpha_{j t s} \times P_{j}^{\max }\right)-P_{j t s}, \forall j, t, s \\
& S R_{j t s} \geq 0 \quad \forall j, t, s \\
& S R_{\text {upstream,ts }}=P_{\text {upstream }}^{\max }-P_{\text {insert } t s} \quad, \forall t, s \\
& S R_{\text {mg,ts }}=\sum_{j=1}^{J} S R_{j t s}+S R_{\text {upstream,ts }}, \forall t, s \\
& S R_{m g, t s} \geq S R_{t s}+\alpha_{D} \times D_{t s}\left(1+\mathrm{e}_{D}^{i}\right)+ \\
& \quad \alpha_{W} \times W_{t s}\left(1+\mathrm{e}_{W}^{i}\right)+ \\
& \quad \alpha_{P V} \times P V_{t s}\left(1+\mathrm{e}_{P V}^{i}\right), \forall t, s
\end{aligned}
$$

The last three terms in the right hand side of Equation (26) are the extra reserve added to mitigate the effects of uncertainties in the forecasted load, wind power, and solar power respectively (Alabedin 2012).

\subsection{Battery constraints}

The Equation (27) is used to calculate $S O C_{t s}$ that determine the charge state of battery at hour $t$ scenario s.

$$
\begin{aligned}
& \operatorname{SOC}_{t s}=\operatorname{SOC}_{(t-1) s}+ \\
& \frac{\left(P_{\text {charge }, t s} \times \eta_{\text {charge } e}\right)-\left(P_{\text {discharge }, t s} / \eta_{\text {discharge }}\right)}{\text { battery }_{\max }}
\end{aligned}
$$

Subject to:

$$
\begin{aligned}
& S O C_{\text {min }} \leq S O C_{t s} \leq S O C_{\text {max }} \\
& 0 \leq P_{\text {charg } e, t s} \leq \xi_{t s} P_{\text {charg } e}^{\max } \\
& 0 \leq P_{\text {discharg } e, t s} \leq P_{\text {discharge }}^{\max }\left(1-\xi_{\text {ts }}\right)
\end{aligned}
$$

\subsection{Modeling of the renewable sources}

Generating power of photovoltaic panels is obtained from the following equation (Logenthiran et al. 2009): 
$P_{\max }^{M}=\frac{G_{a}}{G_{a, 0}}\left[P_{\max , 0}^{M}+\mu_{p \max }\left(T_{a}+G_{a} \times \frac{N O C T-20}{800}-T_{M, 0}\right)\right]$

Where $G_{a, O}$ is the maximum solar radiation, $P_{\max , O}^{M}$ is the maximum power,is the module temperature at $T_{M, O}$ the standard condition and NOCT is the normal operating cell temperature of PV (Logenthiran et al. 2009).

Generating power of wind turbine is calculated as follows:

$P_{\text {out }}=\left\{\begin{array}{lr}0, & V_{W} \leq V_{c i} \\ a \times V_{W}^{4}+b \times V_{W}^{3}+c \times V_{W}^{2}+d \times V_{W}+e, & V_{c i} \leq V_{W} \leq V_{r} \\ P_{r}, & V_{r} \leq V_{W} \leq V_{c o} \\ 0, & V_{W} \geq V_{c o}\end{array}\right.$

Where, $P_{r}, V_{c i} V_{c o}, V_{r}, V_{W}$ are the rated power, cut-in speed, cut-out speed, speed at rated power and wind speed respectively (Logenthiran et al. 2009).

\section{Micro-grid's parameters}

The studied micro-grid is consisted of 4 diesel generator, a wind turbine and a photovoltaic panel. The total installed capacity of the diesel generators is $1.9 \mathrm{MW}$ which their parameters are shown in Table 1 (Alabedin
2012). The ramp rates of all the units are assumed to be equal to maximum power generation of units. The capacity of the wind turbine is equal to $1.1 \mathrm{MW}$ (Alabedin 2012) and its parameters are adapted from (Logenthiran et al. 2009), which are shown in Table 2. The photovoltaic system has a capacity of $200 \mathrm{~kW}$ where, its parameters are obtained from (Logenthiran et al. 2009) and are as shown in Table 3. Data related to wind speed; solar radiation and temperature are obtained from (Logenthiran et al. 2009) and are shown in Table 4. Also in this study, a battery bank with the capacity of $600 \mathrm{~kW}$ is used.

Fig. 1 shows the micro-grid's net demand profile and the net generated power of wind turbines and photovoltaic panels installed in the micro-grids.

The capacity of the line linking the upstream grid and micro-grid is assumed to be equal to $1000 \mathrm{~kW}$ (Alabedin 2012). The price of power exchange with the upstream grid is assumed to be $0.17 \$ / \mathrm{kWh}$. The spinning reserve requirement is equal to $10 \%$ of the load and the price of the reserve is assumed $0.01 \$ / \mathrm{kWh}$. The load forecasting error factor $\alpha_{D}$ is equal to 0.03 , the wind forecasting error factor $\alpha_{W}$ is equal to 0.13 , and the solar forecasting error factor $\alpha_{P V}$ is equal to 0.09 (Alabedin 2012).

Table 1

Diesel generators' parameters.

\begin{tabular}{llllllllll}
\hline Unit & $P_{j}^{\max } \mathbf{( k W )}$ & $P_{j}^{\text {min }}$ & $\mathbf{( k W )}$ & $\mathbf{a}(\mathbf{\$} / \mathbf{h r})$ & $\mathbf{b}(\mathbf{\$} / \mathbf{k W h})$ & $M U T_{j}$ & $M D T_{j}$ & $\mathbf{S T C}$ & $\mathbf{S D C}$ \\
\hline & 600 & 100 & 5 & 4 & 5 & 5 & 35 & 15 \\
2 & 600 & 100 & 5 & 6 & 5 & 5 & 25 & 10 \\
3 & 400 & 100 & 20 & 8 & 5 & 5 & 25 & 10 \\
4 & 300 & 50 & 30 & 10 & 5 & 5 & 35 & 15 \\
\hline
\end{tabular}

Table 2

Wind turbine data (Logenthiran et al. 2009).

\begin{tabular}{ccccccccc}
\hline$P_{r}$ & $\mathrm{~V}_{c i}$ & $v_{r}$ & $v_{c o}$ & $\mathbf{a}$ & $\mathbf{b}$ & $\mathbf{c}$ & $\mathbf{d}$ & $\mathbf{e}$ \\
\hline 140 & 3.0 & 15.01 & 17 & -0.015 & 0.33 & -0.9 & -2.1 & 7.1 \\
\hline
\end{tabular}

Table 3

Photovoltaic panel data (Logenthiran et al. 2009).

\begin{tabular}{|cccc|}
\hline NOCT & No of cells in a plant & Prated W & $\mu_{p \max }$ \\
\hline 44 & $1000^{*} 10$ & 36 & -0.00045
\end{tabular}

Table 4

Metrological data (Logenthiran et al. 2009).

\begin{tabular}{ccccccccc}
\hline Time $(\mathbf{h r})$ & $G_{a} \mathbf{( \mathbf { w } / \mathbf { m } ^ { 2 } )}$ & $T_{a} \mathbf{( C )}$ & $v_{w} \mathbf{( m / s )}$ & Time $(\mathbf{h r})$ & $G_{a} \mathbf{( w / \mathbf { m } ^ { 2 } )}$ & $T_{a}(\mathbf{C})$ & $v_{w}(\mathbf{m} / \mathbf{s})$ \\
\hline 1 & 0 & 24.8 & 5.7 & 13 & 833 & 29.0 & 5.9 \\
2 & 0 & 24.7 & 6.5 & 14 & 850 & 29.7 & 4.9 \\
3 & 0 & 24.5 & 7.5 & 15 & 680 & 29.8 & 3.5 \\
4 & 0 & 24.3 & 6.9 & 16 & 595 & 30.0 & 3.4 \\
5 & 93.5 & 24.4 & 8.6 & 17 & 255 & 29.8 & 2.8 \\
6 & 212.5 & 24.5 & 10.5 & 18 & 212.5 & 29.5 & 3.1 \\
7 & 255 & 25.5 & 13.6 & 19 & 153 & 29.0 & 2.3 \\
8 & 467.5 & 26.5 & 10.4 & 20 & 68 & 27.7 & 2.9 \\
9 & 637.5 & 27.5 & 9.1 & 21 & 42.5 & 26.5 & 3.5 \\
10 & 680 & 28.0 & 9.3 & 22 & 0 & 26.0 & 3.8 \\
11 & 816 & 28.5 & 7.7 & 23 & 0 & 25.5 & 3.8 \\
12 & 850 & 28.8 & 7.0 & 24 & 0 & 25.0 & 4.7 \\
\hline
\end{tabular}




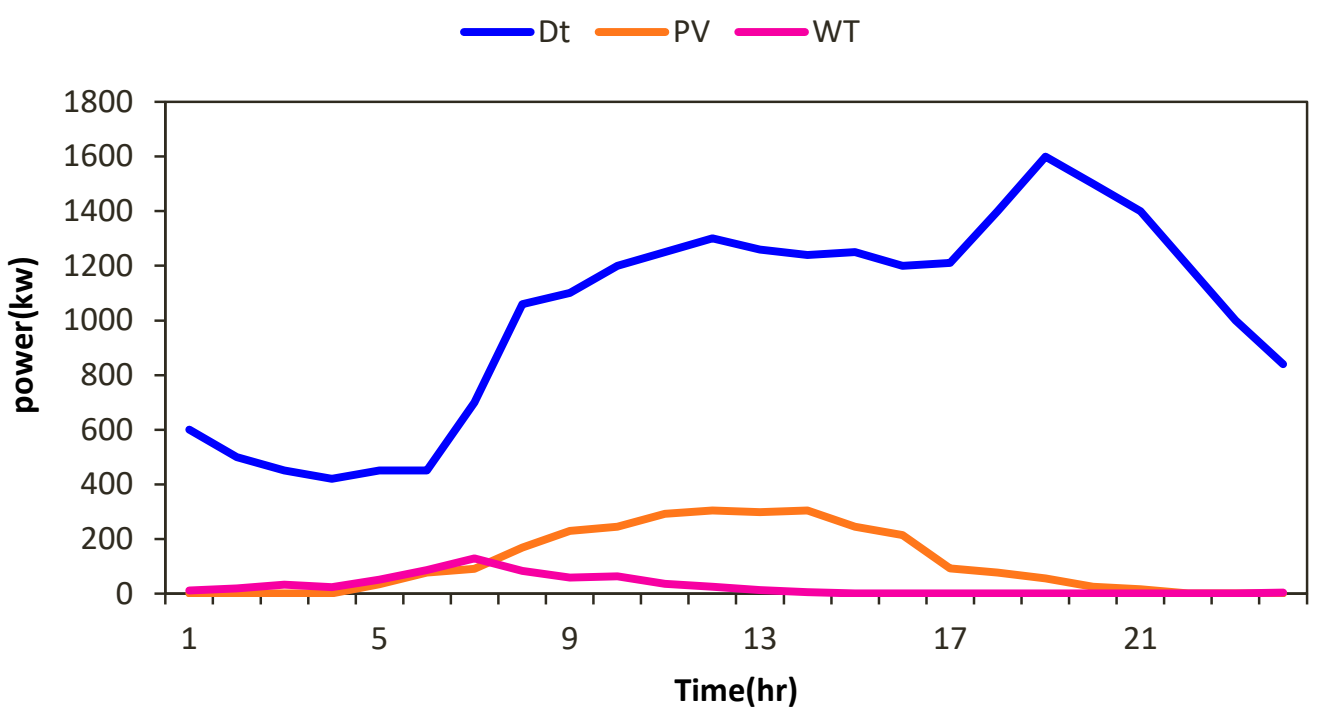

Fig.1. Micro-grid's net demand profile and generated net power of the renewable sources.

Charge/discharge efficiency of the battery, maximum/minimum charge status of the battery are assumed $0.95,0.3$, and 1 , respectively.

The objective function presented in this study was modeled using the GAMS software, and solved using CPLEX solver by mixed-integer programming (MIP) method.

\section{Simulation results}

In this section simulation results will be presented and the operation of the micro-grid evaluated. Also the effects of uncertainties and changing the amount of spinning reserve on the micro-grid's costs will be analyzed. To do a typical micro-grid has been operated in the following cases and the obtained results will be compared:
- $\quad$ First case: micro-grid with renewable energy and considering all kinds of uncertainties;

- Second case: micro-grid without renewable sources;

- Third case: micro-grid with renewable resources and regardless of the uncertainties;

- Fourth case: micro-grid with higher uncertainties;

5.1 First case: micro-grid with renewable energy and considering all kinds of uncertainties

In order to considering the uncertainties, the probability distribution functions of the load, wind power, and solar power forecasting errors are extracted from (Alabedin 2012). The load and wind power PDF have 5 states and the solar power PDF has 3 states as shown in the Table 5 .

Table 5

The sets of the probability distribution functions representing the forecasting errors.

\begin{tabular}{cccccc}
\hline $\begin{array}{c}\text { Load } \\
\begin{array}{c}\text { \% of deviation from } \\
\text { forecast }\end{array}\end{array}$ & Probability & $\begin{array}{c}\text { \% of deviation from } \\
\text { forecast }\end{array}$ & Probability & $\begin{array}{c}\text { \% of deviation from } \\
\text { forecast }\end{array}$ & Probability \\
\hline-2 & 0.05 & -2.5 & 0.10 & -1.5 & 0.15 \\
-1.5 & 0.15 & -1 & 0.15 & 0.0 & 0.70 \\
0 & 0.60 & 0 & 0.50 & +1.5 & 0.15 \\
+2 & 0.15 & +1 & 0.15 & - & - \\
+3 & 0.05 & +2.5 & 0.10 & - & - \\
\hline
\end{tabular}

Using a two-stage scenario tree, 75 scenarios are generated. A complete list of the scenarios and their probabilities is provided in Table 6 .
In this case, in order to analyzing the operation of understudy network, simulation has been carried out for two different profiles of load and renewable based power generation as shown in Fig. 2 and Fig. 3. These two profiles are related to the cases of excess demand and excess renewable based generation. 
Table 6

The generated 75 scenarios and their probabilities in first case.

\begin{tabular}{|c|c|c|c|c|c|c|c|c|c|}
\hline Scn. & $\begin{array}{c}\text { Solar } \\
(\%)\end{array}$ & $\begin{array}{c}\text { Load } \\
(\%)\end{array}$ & $\begin{array}{c}\text { Wind } \\
(\%)\end{array}$ & Prob & Scn. & $\begin{array}{c}\text { Solar } \\
(\%)\end{array}$ & $\begin{array}{c}\text { Load } \\
(\%)\end{array}$ & $\begin{array}{c}\text { Wind } \\
(\%)\end{array}$ & Prob \\
\hline 1 & -1.5 & -2 & -2.5 & 0.00075 & 39 & 0 & 0 & 1 & 0.063 \\
\hline 2 & -1.5 & -2 & -1 & 0.001125 & 40 & 0 & 0 & 2.5 & 0.042 \\
\hline 3 & -1.5 & -2 & 0 & 0.00375 & 41 & 0 & 2 & -2.5 & 0.0105 \\
\hline 4 & -1.5 & -2 & 1 & 0.001125 & 42 & 0 & 2 & -1 & 0.01575 \\
\hline 5 & -1.5 & -2 & 2.5 & 0.00075 & 43 & 0 & 2 & 0 & 0.0525 \\
\hline 6 & -1.5 & -1.5 & -2.5 & 0.00225 & 44 & 0 & 2 & 1 & 0.01575 \\
\hline 7 & -1.5 & -1.5 & -1 & 0.003375 & 45 & 0 & 2 & 2.5 & 0.0105 \\
\hline 8 & -1.5 & -1.5 & 0 & 0.01125 & 46 & 0 & 3 & -2.5 & 0.0035 \\
\hline 9 & -1.5 & -1.5 & 1 & 0.003375 & 47 & 0 & 3 & -1 & 0.00525 \\
\hline 10 & -1.5 & -1.5 & 2.5 & 0.00225 & 48 & 0 & 3 & 0 & 0.0175 \\
\hline 11 & -1.5 & 0 & -2.5 & 0.009 & 49 & 0 & 3 & 1 & 0.00525 \\
\hline 12 & -1.5 & 0 & -1 & 0.0135 & 50 & 0 & 3 & 2.5 & 0.0035 \\
\hline 13 & -1.5 & 0 & 0 & 0.045 & 51 & 1.5 & -2 & -2.5 & 0.00075 \\
\hline 14 & -1.5 & 0 & 1 & 0.0135 & 52 & 1.5 & -2 & -1 & 0.001125 \\
\hline 15 & -1.5 & 0 & 2.5 & 0.009 & 53 & 1.5 & -2 & 0 & 0.00375 \\
\hline 16 & -1.5 & 2 & -2.5 & 0.00225 & 54 & 1.5 & -2 & 1 & 0.001125 \\
\hline 17 & -1.5 & 2 & -1 & 0.003375 & 55 & 1.5 & -2 & 2.5 & 0.00075 \\
\hline 18 & -1.5 & 2 & 0 & 0.01125 & 56 & 1.5 & -1.5 & -2.5 & 0.00225 \\
\hline 19 & -1.5 & 2 & 1 & 0.003375 & 57 & 1.5 & -1.5 & -1 & 0.003375 \\
\hline 20 & -1.5 & 2 & 2.5 & 0.00225 & 58 & 1.5 & -1.5 & 0 & 0.01125 \\
\hline 21 & -1.5 & 3 & -2.5 & 0.00075 & 59 & 1.5 & -1.5 & 1 & 0.003375 \\
\hline 22 & -1.5 & 3 & -1 & 0.001125 & 60 & 1.5 & -1.5 & 2.5 & 0.00225 \\
\hline 23 & -1.5 & 3 & 0 & 0.00375 & 61 & 1.5 & 0 & -2.5 & 0.009 \\
\hline 24 & -1.5 & 3 & 1 & 0.001125 & 62 & 1.5 & 0 & -1 & 0.0135 \\
\hline 25 & -1.5 & 3 & 2.5 & 0.00075 & 63 & 1.5 & 0 & 0 & 0.045 \\
\hline 26 & 0 & -2 & -2.5 & 0.0035 & 64 & 1.5 & 0 & 1 & 0.0135 \\
\hline 27 & 0 & -2 & -1 & 0.00525 & 65 & 1.5 & 0 & 2.5 & 0.009 \\
\hline 28 & 0 & -2 & 0 & 0.0175 & 66 & 1.5 & 2 & -2.5 & 0.00225 \\
\hline 29 & 0 & -2 & 1 & 0.00525 & 67 & 1.5 & 2 & -1 & 0.003375 \\
\hline 30 & 0 & -2 & 2.5 & 0.0035 & 68 & 1.5 & 2 & 0 & 0.01125 \\
\hline 31 & 0 & -1.5 & -2.5 & 0.0105 & 69 & 1.5 & 2 & 1 & 0.003375 \\
\hline 32 & 0 & -1.5 & -1 & 0.01575 & 70 & 1.5 & 2 & 2.5 & 0.00225 \\
\hline 33 & 0 & -1.5 & 0 & 0.0525 & 71 & 1.5 & 3 & -2.5 & 0.00075 \\
\hline 34 & 0 & -1.5 & 1 & 0.01575 & 72 & 1.5 & 3 & -1 & 0.001125 \\
\hline 35 & 0 & -1.5 & 2.5 & 0.0105 & 73 & 1.5 & 3 & 0 & 0.00375 \\
\hline 36 & 0 & 0 & -2.5 & 0.042 & 74 & 1.5 & 3 & 1 & 0.001125 \\
\hline 37 & 0 & 0 & -1 & 0.063 & 75 & 1.5 & 3 & 2.5 & 0.00075 \\
\hline 38 & 0 & 0 & 0 & 0.21 & & & & & \\
\hline
\end{tabular}

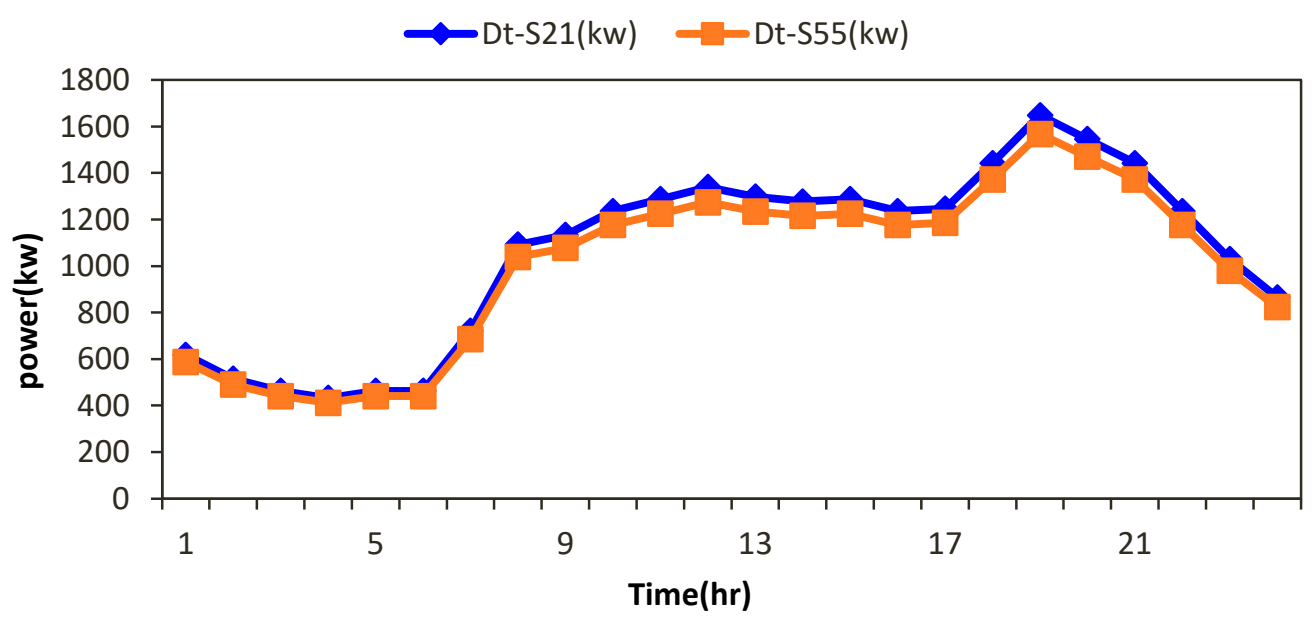

Fig. 2. Forecasted demand during the excess demand profile and the excess renewable generation profile in first case. 
Citation: Jasemi, M., Adabi, F., Mozafari, B., Salahi, S. (2016). Optimal Operation of Micro-grids Considering the Uncertainties of Demand and Renewable Energy Resources Generation. Int. Journal of Renewable Energy Development, 5(3), 233-248, doi: 10.14710/ijred.5.3.233-248

$P$ a g e $\mid 240$

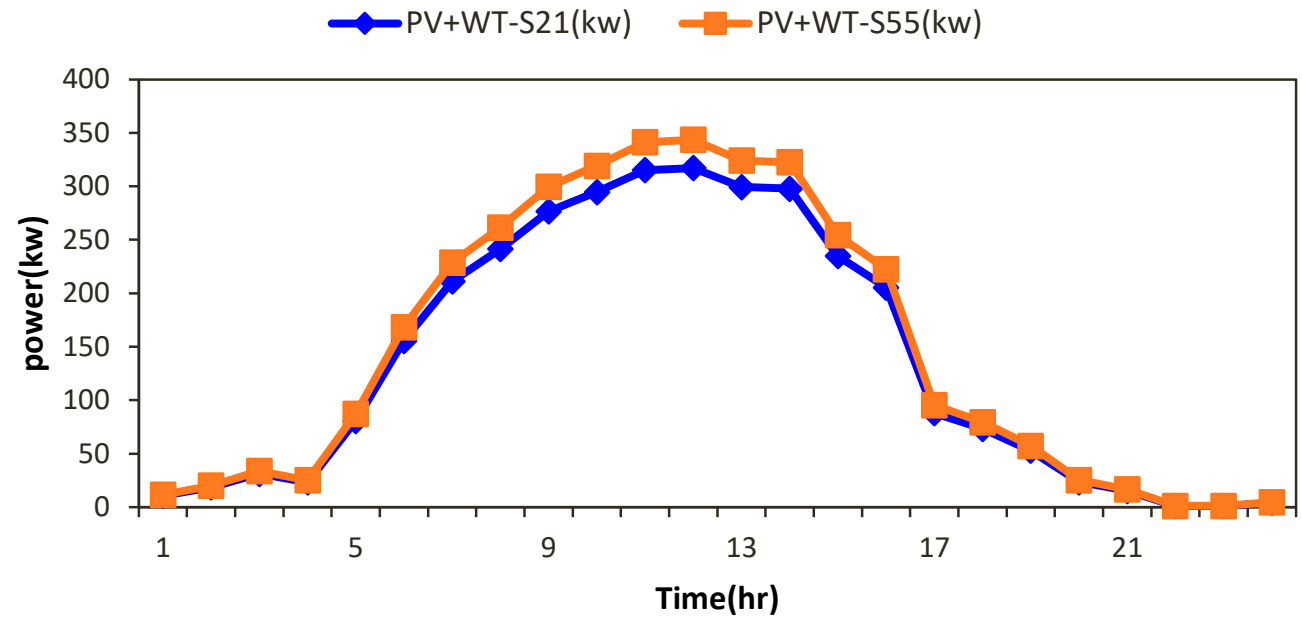

Fig. 3. Forecasted renewable energy during the excess demand profile and the excess renewable generation profile in first case.

Figure 2 shows forecasted demand during the excess demand profile (scenario 21) and the excess renewable generation profile (scenario 55). Figure 3 shows forecasted renewable energy for above mentioned scenarios.
Figures 4 and 6 are showing the solution of the unit commitment problem for the excess demand and the excess renewable generation scenarios, respectively. Also, Figures 5 and 7 are showing the charge status of battery during 24 hours in this case, respectively.

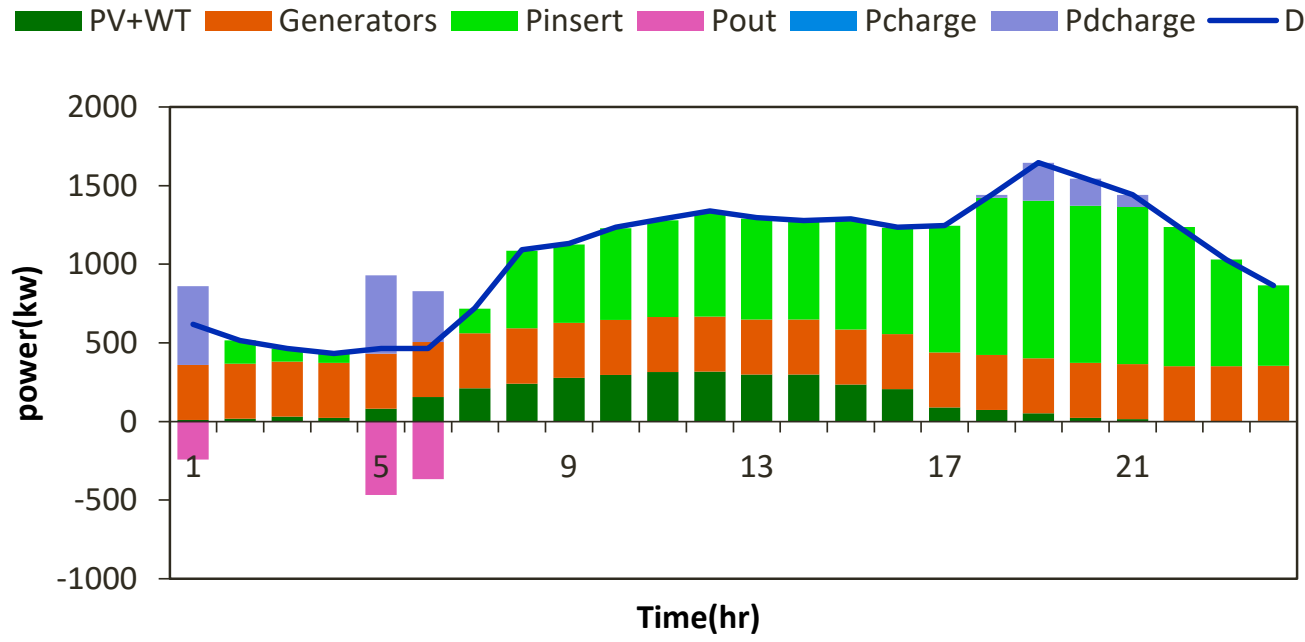

Fig. 4. The results of the micro-grid operation in the excess demand scenario of first case.

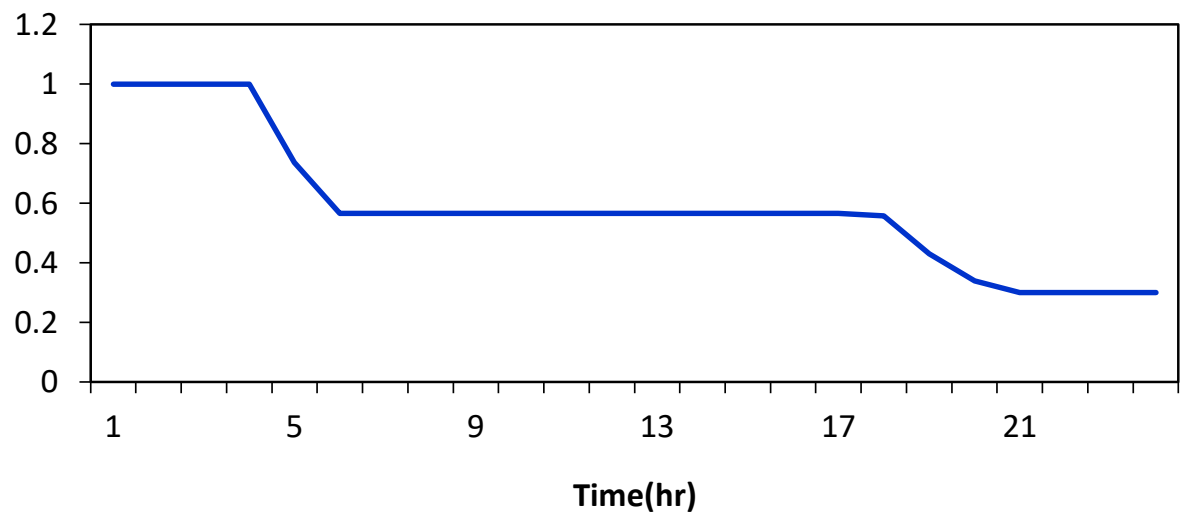

Fig. 5 The charge status of battery in the excess demand scenario of first case. 


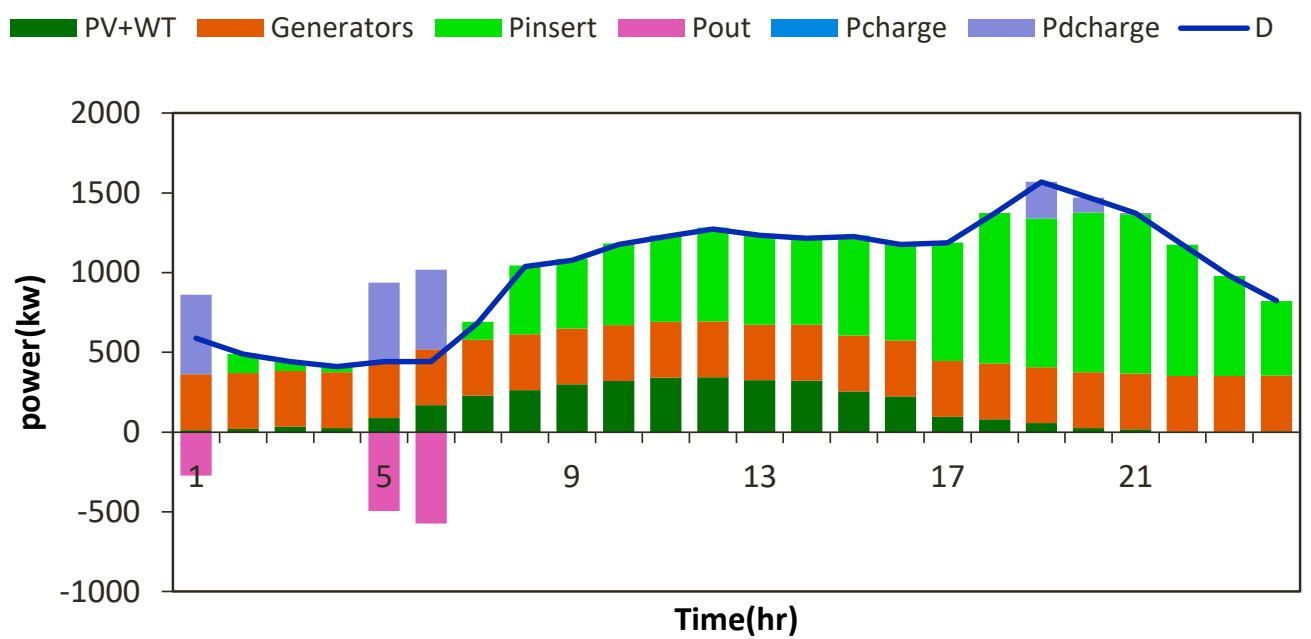

Fig. 6. The results of the micro-grid operation in the excess renewable generation scenario of first case.

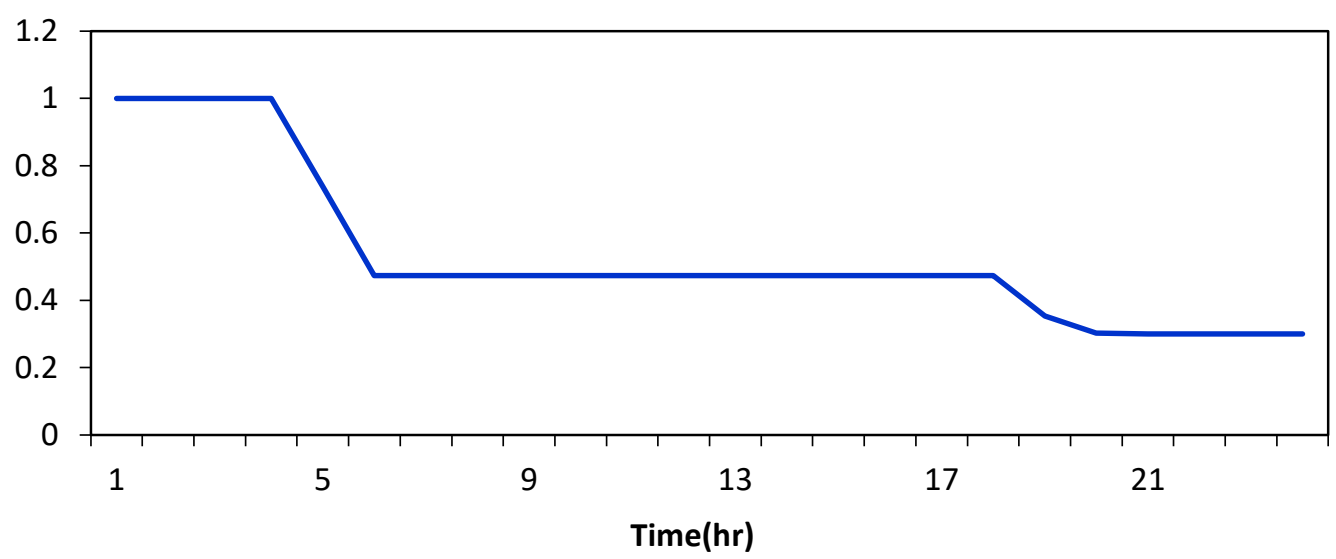

Fig. 7. The charge status of battery in the excess renewable generation scenario of first case.

\subsection{Second case: micro-grid without renewable sources}

In this case, in order to evaluate the effects of renewable resources on operation schedule and costs, the load profile shown in Fig.2 is used. Figures 8 and 10 are showing the solution of the unit commitment problem for the worst and best scenarios, respectively. Figures 9 and 11 are showing the charge status of battery for the worst and best scenarios, respectively.

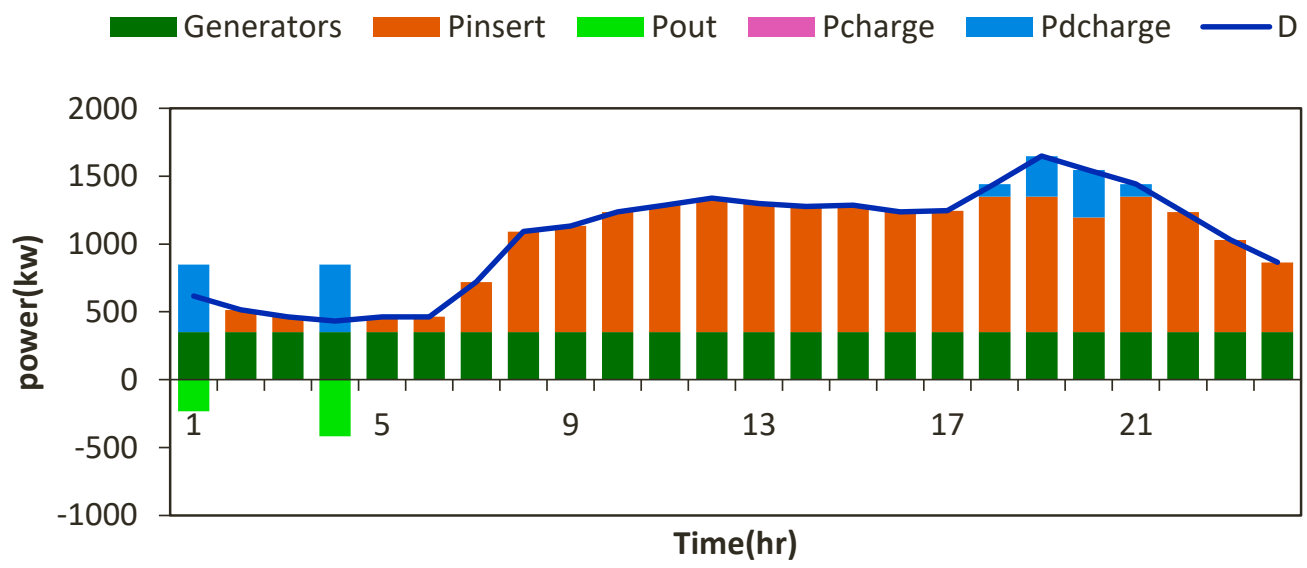

Fig. 8. The results of the micro-grid operation in the worst scenario in second case. 


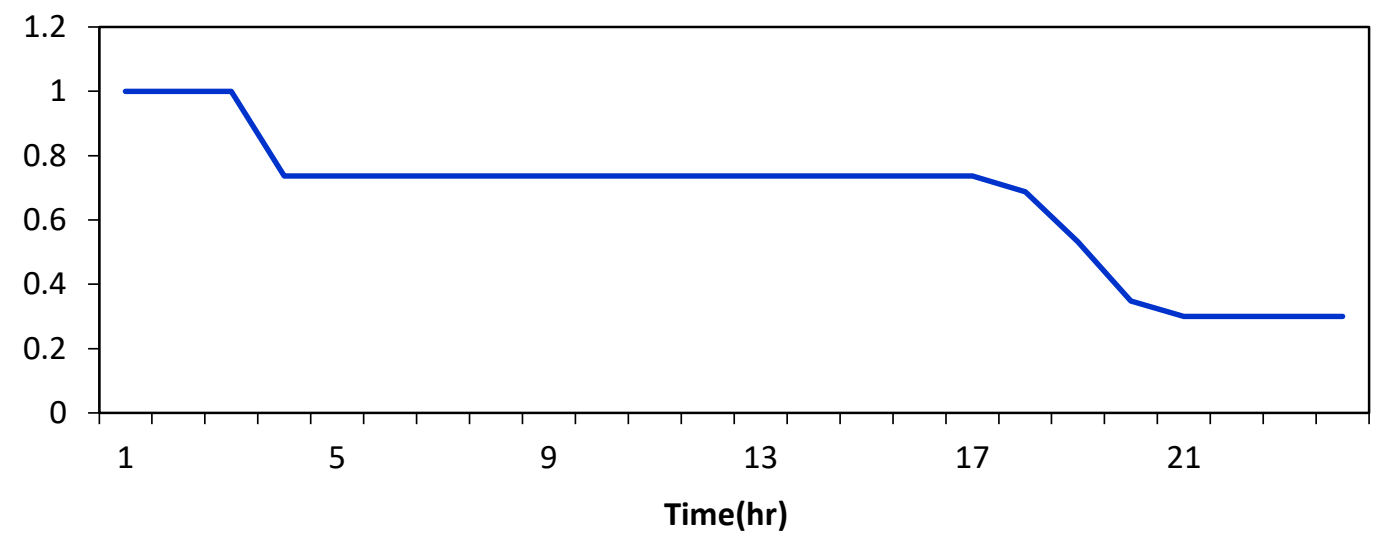

Fig. 9. The charge status of battery in the worst scenario in second case.

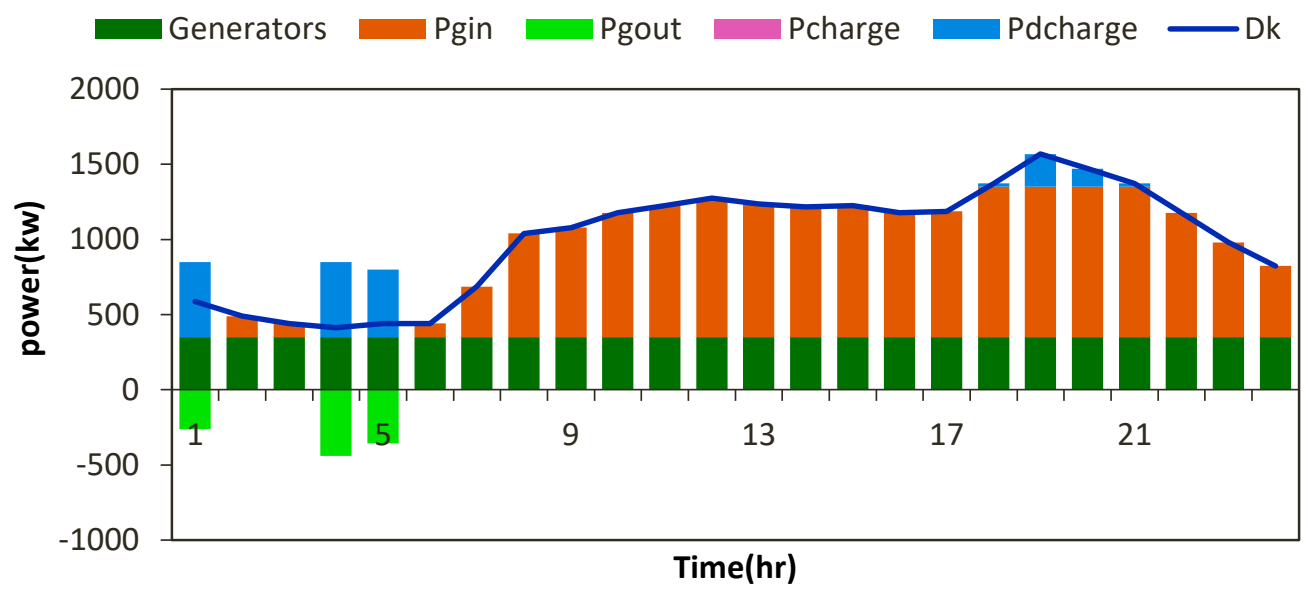

Fig. 10. The results of the micro-grid operation in the best scenario in second case.

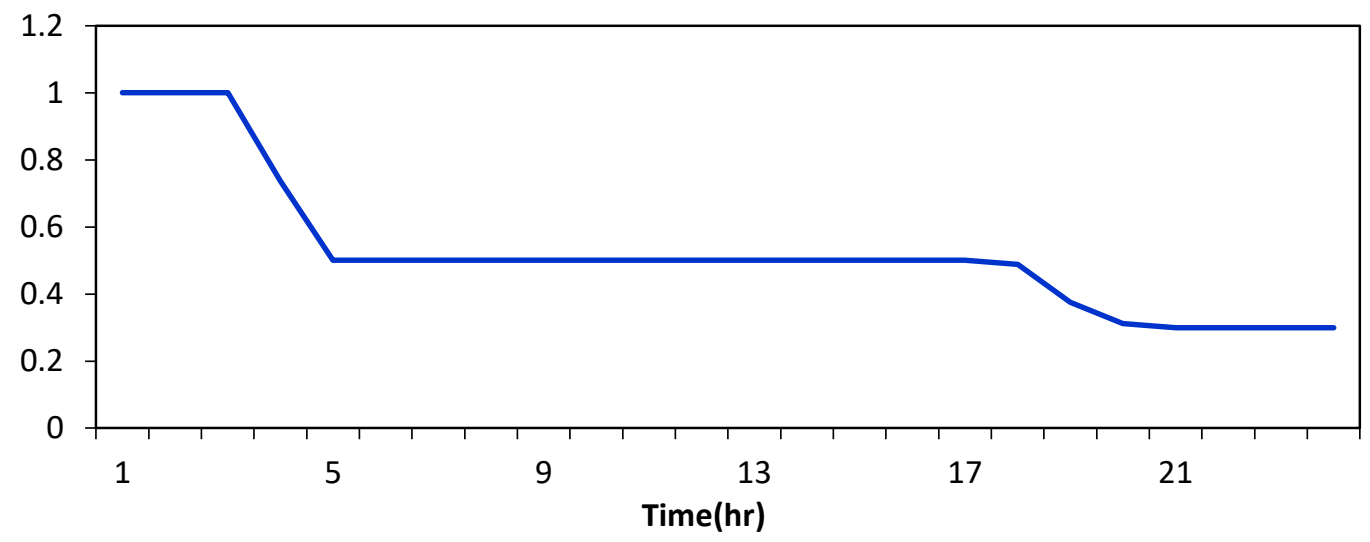

Fig. 11. The charge status of battery in the best scenario in second case.

\subsection{Third case: micro-grid with renewable resources and regardless of the uncertainties}

In this case, the load and the renewable power generation profiles shown in Fig.1 are used. Fig.12 shows the results of the micro-grid operation in third case. The charge status of battery during 24 hours in this case is shown in Fig. 13.

\subsection{Fourth case: micro-grid with higher uncertainties}

In this case, uncertainties are assumed higher compared to the first case. The sets of the new probability distribution functions are shown in Table 7 (Alabedin 2012). So, a new set of scenarios is generated. A complete list of all the scenarios generated and their probabilities is provided in Table 8 (Alabedin 2012). 
Fig. 14 shows forecasted demand during the excess demand profile and the excess renewable generation profile. Fig.15 shows forecasted renewable energy for above mentioned scenarios.

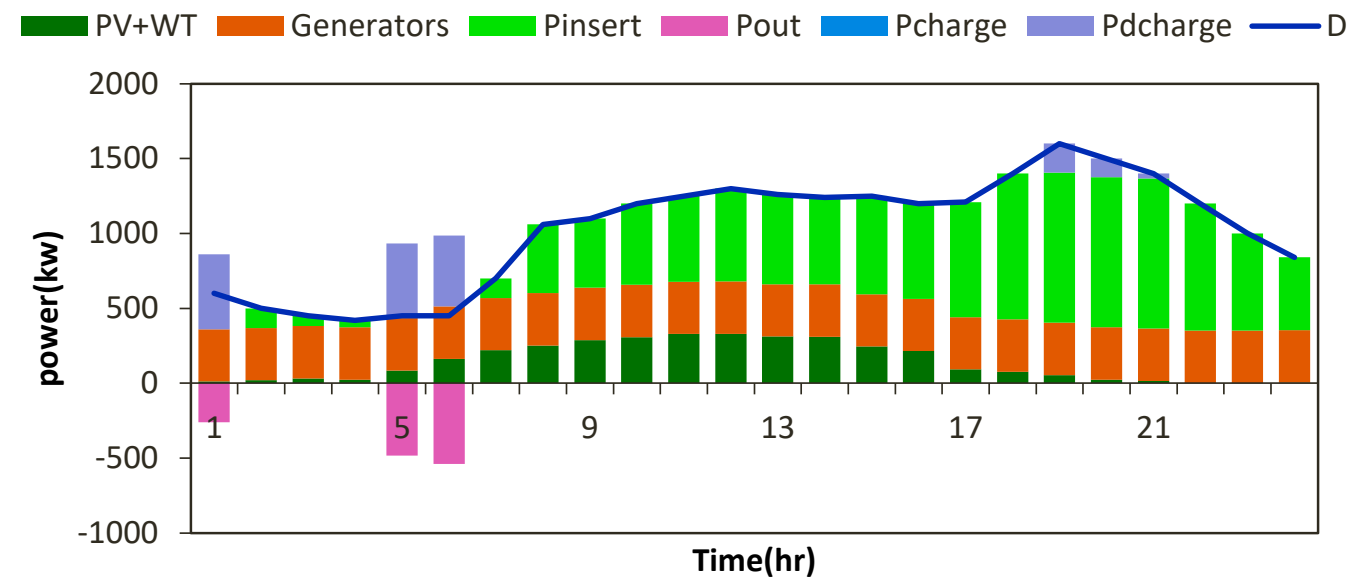

Fig.12. The results of the micro-grid operation in third case.

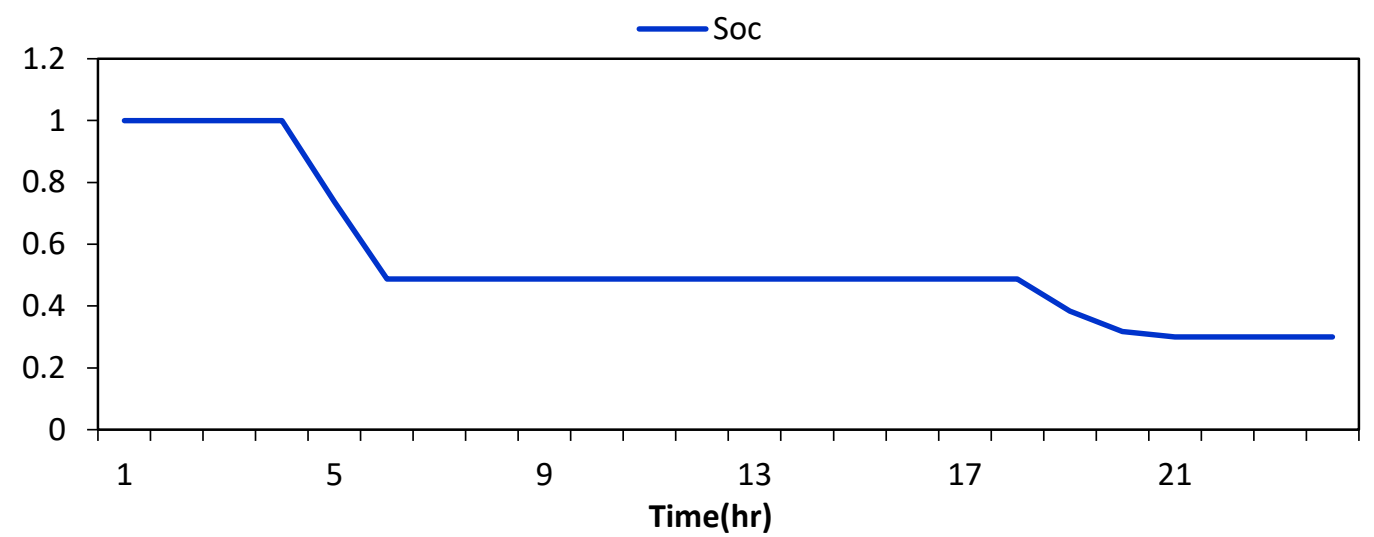

Fig. 13. The charge status of battery in third case.

Table 7

The sets of the probability distribution functions representing forecasting errors with higher uncertainties.

\begin{tabular}{cccccc} 
Load & \multicolumn{2}{c}{ Wind } & \multicolumn{2}{c}{ Solar } \\
\% of deviation from forecast & Probability & \% of deviation from forecast & Probability & \% of deviation from forecast & Probability \\
\hline-3.0 & 0.05 & -3.5 & 0.1 & -2.5 & 0.15 \\
-2.5 & 0.15 & -2 & 0.15 & 1 & 0.70 \\
1 & 0.6 & 1 & 0.5 & +2.5 & 0.15 \\
+3.0 & 0.15 & +2 & 0.15 & - & - \\
+4.0 & 0.05 & +3.5 & & - & - \\
\hline
\end{tabular}

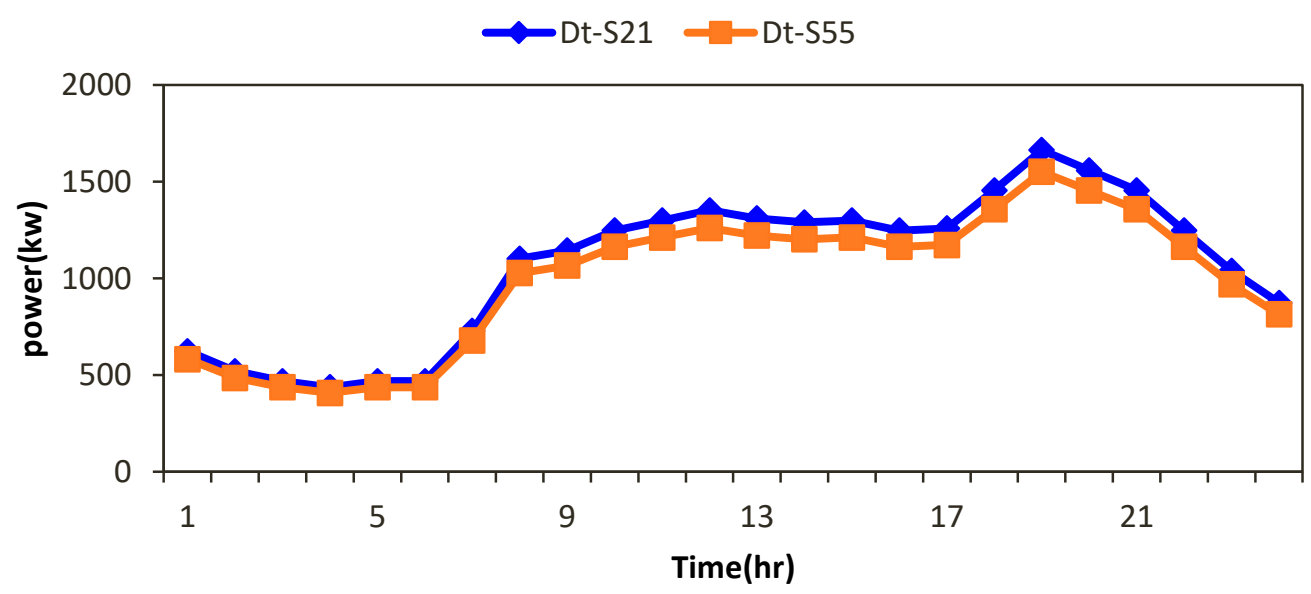

Fig.14. Forecasted demand during the excess demand profile and the excess renewable generation profile in fourth case. 
Citation: Jasemi, M., Adabi, F., Mozafari, B., Salahi, S. (2016). Optimal Operation of Micro-grids Considering the Uncertainties of Demand and Renewable Energy Resources Generation. Int. Journal of Renewable Energy Development, 5(3), 233-248, doi: 10.14710/ijred.5.3.233-248

$P$ a g e $\mid 244$

Figures 16 and 18 shows the results of the micro-grid operation during the excess demand scenario and the excess renewable generation profile in fourth case, respectively. Figures 17 and 19 shows the charge status of battery during the excess demand scenario and the excess renewable generation profile in fourth case, respectively.

\section{Table 8}

\begin{tabular}{|c|c|c|c|c|c|c|c|c|c|}
\hline Scn. & Solar (\%) & Load (\%) & Wind (\%) & Prob & Scn. & Solar (\%) & Load (\%) & Wind (\%) & Prob \\
\hline 1 & -2.5 & -3 & -3.5 & 0.00075 & 39 & 1 & 1 & 2 & 0.063 \\
\hline 2 & -2.5 & -3 & -2 & 0.001125 & 40 & 1 & 1 & 3.5 & 0.042 \\
\hline 3 & -2.5 & -3 & 1 & 0.00375 & 41 & 1 & 3 & -3.5 & 0.0105 \\
\hline 4 & -2.5 & -3 & 2 & 0.001125 & 42 & 1 & 3 & -2 & 0.01575 \\
\hline 5 & -2.5 & -3 & 3.5 & 0.00075 & 43 & 1 & 3 & 1 & 0.0525 \\
\hline 6 & -2.5 & -2.5 & -3.5 & 0.00225 & 44 & 1 & 3 & 2 & 0.01575 \\
\hline 7 & -2.5 & -2.5 & -2 & 0.003375 & 45 & 1 & 3 & 3.5 & 0.0105 \\
\hline 8 & -2.5 & -2.5 & 1 & 0.01125 & 46 & 1 & 4 & -3.5 & 0.0035 \\
\hline 9 & -2.5 & -2.5 & 2 & 0.003375 & 47 & 1 & 4 & -2 & 0.00525 \\
\hline 10 & -2.5 & -2.5 & 3.5 & 0.00225 & 48 & 1 & 4 & 1 & 0.0175 \\
\hline 11 & -2.5 & 1 & -3.5 & 0.009 & 49 & 1 & 4 & 2 & 0.00525 \\
\hline 12 & -2.5 & 1 & -2 & 0.0135 & 50 & 1 & 4 & 3.5 & 0.0035 \\
\hline 13 & -2.5 & 1 & 1 & 0.045 & 51 & 2.5 & -3 & -3.5 & 0.00075 \\
\hline 14 & -2.5 & 1 & 2 & 0.0135 & 52 & 2.5 & -3 & -2 & 0.001125 \\
\hline 15 & -2.5 & 1 & 3.5 & 0.009 & 53 & 2.5 & -3 & 1 & 0.00375 \\
\hline 16 & -2.5 & 3 & -3.5 & 0.00225 & 54 & 2.5 & -3 & 2 & 0.001125 \\
\hline 17 & -2.5 & 3 & -2 & 0.003375 & 55 & 2.5 & -3 & 3.5 & 0.00075 \\
\hline 18 & -2.5 & 3 & 1 & 0.01125 & 56 & 2.5 & -2.5 & -3.5 & 0.00225 \\
\hline 19 & -2.5 & 3 & 2 & 0.003375 & 57 & 2.5 & -2.5 & -2 & 0.003375 \\
\hline 20 & -2.5 & 3 & 3.5 & 0.00225 & 58 & 2.5 & -2.5 & 1 & 0.01125 \\
\hline 21 & -2.5 & 4 & -3.5 & 0.00075 & 59 & 2.5 & -2.5 & 2 & 0.003375 \\
\hline 22 & -2.5 & 4 & -2 & 0.001125 & 60 & 2.5 & -2.5 & 3.5 & 0.00225 \\
\hline 23 & -2.5 & 4 & 1 & 0.00375 & 61 & 2.5 & 1 & -3.5 & 0.009 \\
\hline 24 & -2.5 & 4 & 2 & 0.001125 & 62 & 2.5 & 1 & -2 & 0.0135 \\
\hline 25 & -2.5 & 4 & 3.5 & 0.00075 & 63 & 2.5 & 1 & 1 & 0.045 \\
\hline 26 & 1 & -3 & -3.5 & 0.0035 & 64 & 2.5 & 1 & 2 & 0.0135 \\
\hline 27 & 1 & -3 & -2 & 0.00525 & 65 & 2.5 & 1 & 3.5 & 0.009 \\
\hline 28 & 1 & -3 & 1 & 0.0175 & 66 & 2.5 & 3 & -3.5 & 0.00225 \\
\hline 29 & 1 & -3 & 2 & 0.00525 & 67 & 2.5 & 3 & -2 & 0.003375 \\
\hline 30 & 1 & -3 & 3.5 & 0.0035 & 68 & 2.5 & 3 & 1 & 0.01125 \\
\hline 31 & 1 & -2.5 & -3.5 & 0.0105 & 69 & 2.5 & 3 & 2 & 0.003375 \\
\hline 32 & 1 & -2.5 & -2 & 0.01575 & 70 & 2.5 & 3 & 3.5 & 0.00225 \\
\hline 33 & 1 & -2.5 & 1 & 0.0525 & 71 & 2.5 & 4 & -3.5 & 0.00075 \\
\hline 34 & 1 & -2.5 & 2 & 0.01575 & 72 & 2.5 & 4 & -2 & 0.001125 \\
\hline 35 & 1 & -2.5 & 3.5 & 0.0105 & 73 & 2.5 & 4 & 1 & 0.00375 \\
\hline 36 & 1 & 1 & -3.5 & 0.042 & 74 & 2.5 & 4 & 2 & 0.001125 \\
\hline 37 & 1 & 1 & -2 & 0.063 & 75 & 2.5 & 4 & 3.5 & 0.00075 \\
\hline 38 & 1 & 1 & 1 & 0.21 & & & & & \\
\hline
\end{tabular}

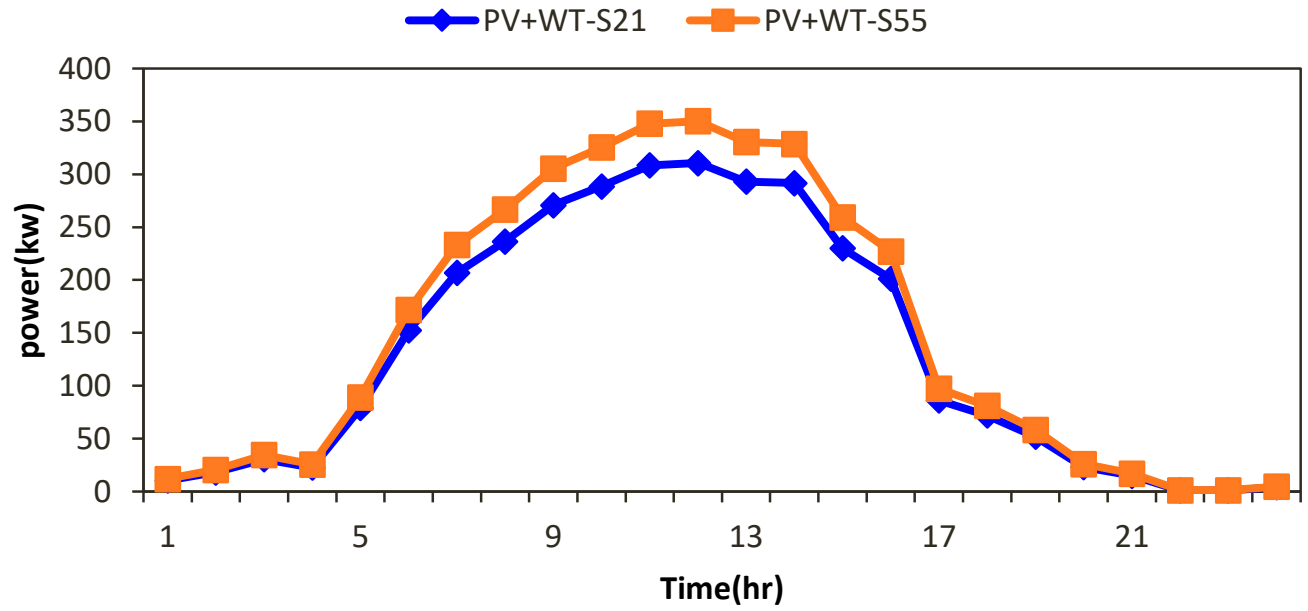

Fig.15. Generated power of the renewable sources and the created scenarios in fourth case. 


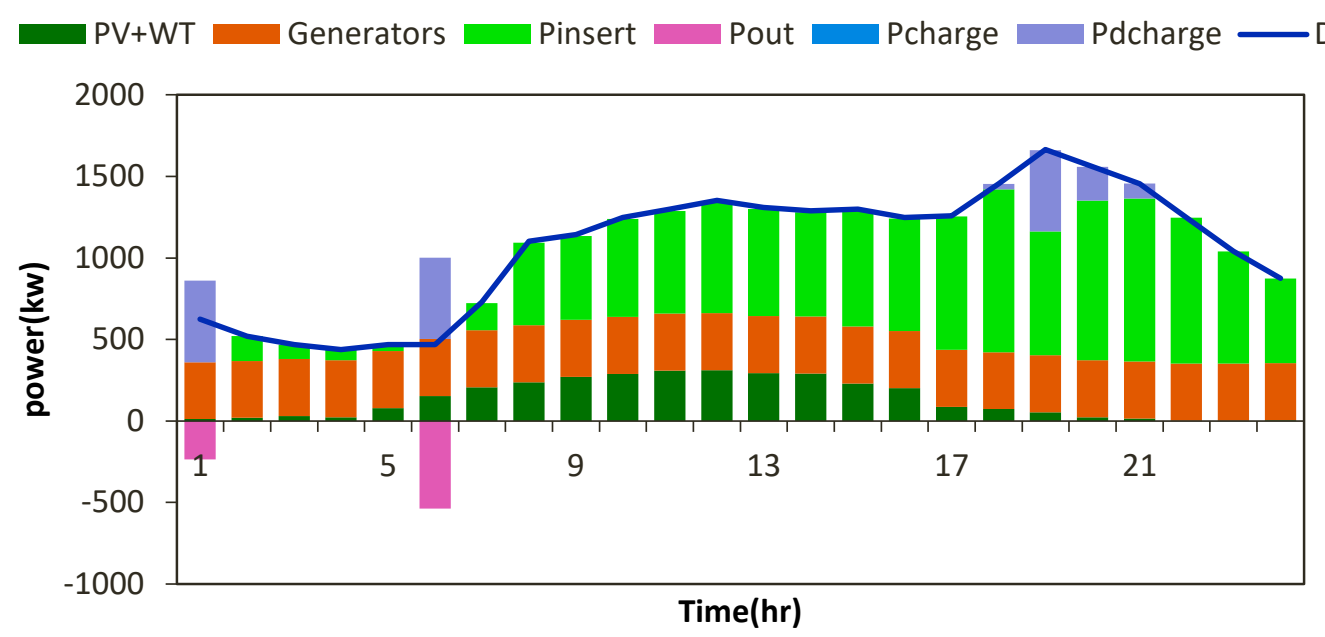

Fig. 16. The results of the micro-grid operation in the excess demand scenario of fourth case.

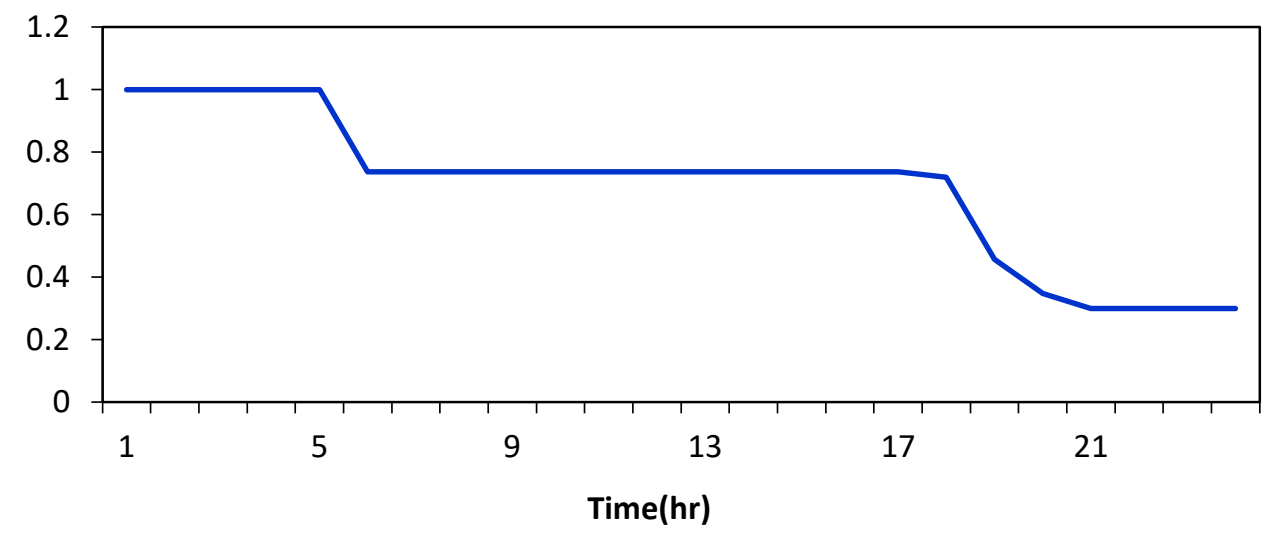

Fig.17. The charge status of battery in the excess demand scenario of fourth case.

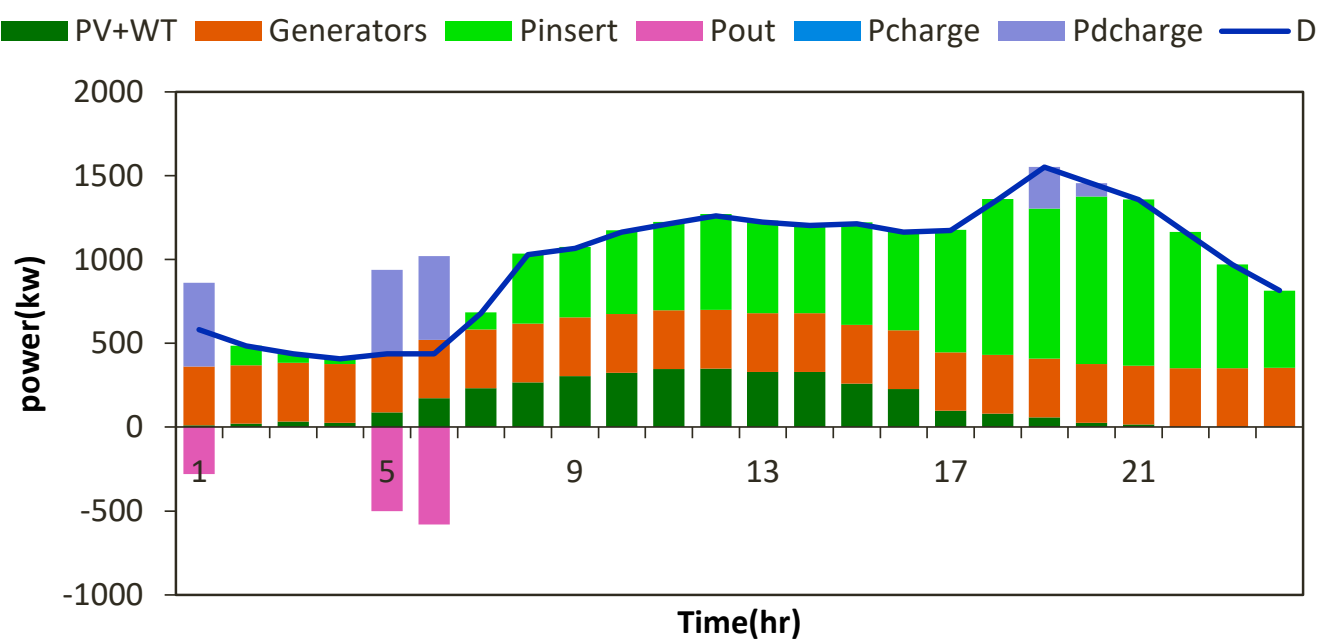

Fig. 18. The results of the micro-grid operation in the excess renewable generation scenario of fourth case.

\subsection{Comparison of four studied cases}

For comparing the results of studied cases, total costs of the micro-grid including diesel generators operating costs, spinning reserve cost, cost of importing power from the upstream grid minus revenue received from selling power to the upstream grid are calculated in each case. Table 9 summaries the results. 


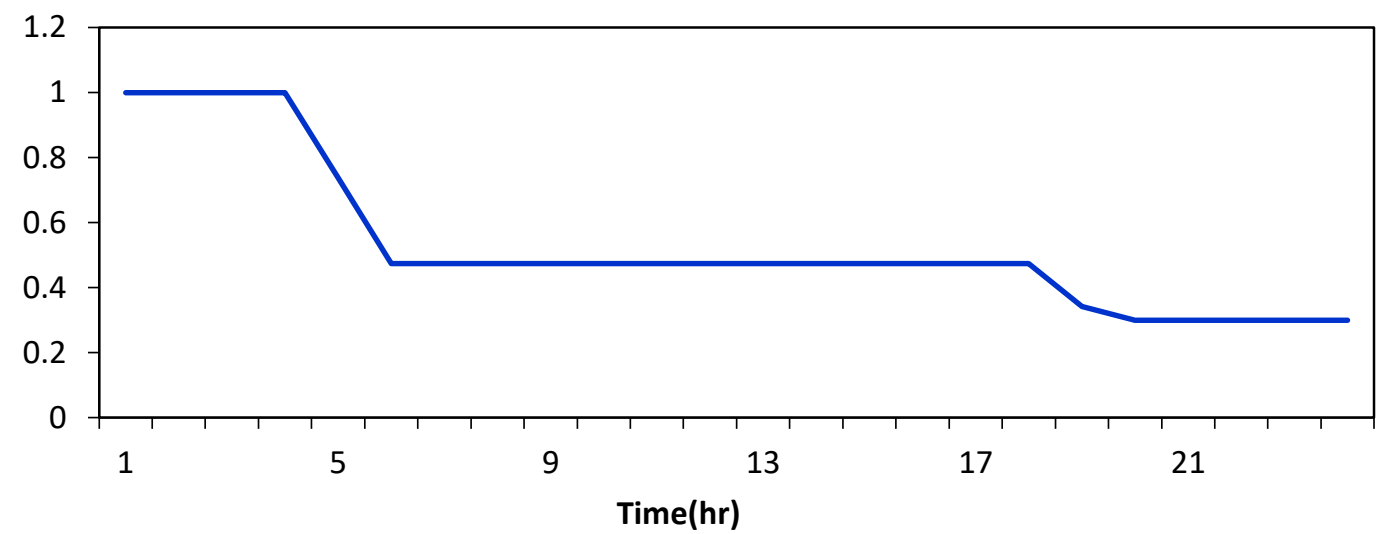

Fig.19. The charge status of battery in the excess renewable generation scenario of fourth case.

Table 9.

The costs of micro-grid operation in studied cases.

\begin{tabular}{cccccc} 
Case & $\begin{array}{c}\text { Total cost } \\
(\$)\end{array}$ & $\begin{array}{c}\text { diesel } \\
\text { generators cost } \\
(\$)\end{array}$ & $\begin{array}{c}\text { Spinning reserve } \\
\text { cost }(\$)\end{array}$ & $\begin{array}{c}\text { The cost of power purchased } \\
\text { from the upstream grid (\$) }\end{array}$ & $\begin{array}{c}\text { The revenue of power sold } \\
\text { to the upstream grid (\$) }\end{array}$ \\
\hline First case & 4425500.693 & 4248000 & 36709.435 & 156239.608 & 15802.361 \\
Second case & 4466697.645 & 4248000 & 34437.653 & 194859.908 & 10957.223 \\
Third case & 4424583.424 & 4248000 & 36732.424 & 155848.793 & 16351.731 \\
Fourth case & 4425650.211 & 4248000 & 36720.087 & 156058.513 & 15128.389 \\
\hline
\end{tabular}

By comparing the base case (first case) to the 2nd-4th cases, we can see that the total costs and the cost of power purchased from the upstream grid in the 2th case are more than the other cases. In the 3rd case in which uncertainties is not considered, the total costs and the cost of power purchased from the upstream grid have significantly been decreased, which it reflects the importance of the uncertainties effects on the microgrids costs. Also due to zero fuel cost of renewable resources, the total costs and the costs of power purchased from the upstream grid in the 2nd case are more than the 3rd case.

The micro-grid revenue from the power sold to the upstream grid in the third cease is more than the other cases. Also, the micro-grid revenue in the 2 nd case is lower than other cases. Decreased cost for the power purchased from the upstream grid and increased revenue of the power sold to the upstream grid in the 3rd case as compared to the 2nd case represent the importance of renewable energy resources to supply micro-grids' demand.

\subsection{Analysis of necessary spinning reserve changes on micro-grid costs}

In this section, we analyze the effects of changing the spinning reserve requirement on the micro-grid's costs. The unit commitment problem is solved for different amounts of spinning reserve. The spinning reserve is considered as a percentage of the total demand from $0 \%$ to $30 \%$ in steps of $10 \%$. Table 10 shows the operating costs when various spinning reserves are needed. According to Table 10, the need to spinning reserve doesn't affect the operating costs.

Table 10

operation costs of micro-grid for different amounts of spinning reserve requirement.

\begin{tabular}{|c|c|c|c|c|}
\hline The amount of reserve & $\begin{array}{l}0 \% \text { of the total } \\
\text { demand }\end{array}$ & $\begin{array}{l}10 \% \text { of the total } \\
\text { demand }\end{array}$ & $\begin{array}{l}20 \% \text { of the total } \\
\text { demand }\end{array}$ & $\begin{array}{l}30 \% \text { of the total } \\
\text { demand }\end{array}$ \\
\hline The total costs of the micro-grid operation (\$) & 4425500.693 & 4425500.693 & 4425500.693 & 4425500.693 \\
\hline The spinning reserve cost (\$) & 36709.435 & 36709.435 & 36709.435 & 36709.435 \\
\hline The cost of the diesel generators operation $(\$)$ & 4248000 & 4248000 & 4248000 & 4248000 \\
\hline $\begin{array}{l}\text { The cost of power purchased from the upstream grid } \\
\text { (\$) }\end{array}$ & 156239.608 & 156239.608 & 156239.608 & 156239.608 \\
\hline The revenue of power sold to the upstream grid (\$) & 15802.361 & 15802.361 & 15802.361 & 15802.361 \\
\hline
\end{tabular}




\section{Conclusion}

In this paper, an optimization model is presented to solve the day-ahead unit commitment problem for operating a typical micro-grid connected to the upstream grid. Load and renewable generation forecasting errors uncertainties were considered in two ways: apportioning supplementary amounts of spinning reserve, and by formulating the unit commitment problem as a multi-scenario stochastic model. In order to evaluate the effects of uncertainties and spinning reserve on the total operation costs, the operation of understudied network was analyzed considering four different cases as bellow:

- $\quad$ First case: micro-grid with renewable energy and considering all kinds of uncertainties;

- Second case: micro-grid without renewable sources;

- Third case: micro-grid with renewable resources and regardless of the uncertainties;

- Fourth case: micro-grid with higher uncertainties;

Comparing the results, it was shown that, the total operation costs of micro-grid in the second, third and fourth cases were $0.93 \%, 0.02 \%$ and $0.0033 \%$ more than first case respectively.

If we compare second and third case for examine the effect of renewable sources on total costs, we found that the total costs of micro-grid operation in the third case (that there is renewable energy based DG units) $0.94 \%$ has decrease comparing to second case.

Also in this study, the effects of changing the spinning reserve requirement on the micro-grid's costs are analyzed. To do that, the unit commitment problem solved for four different amounts of spinning reserve. By comparing the obtained results, it was shown that spinning reserve is ineffective on costs of the micro-grid operating.

\begin{tabular}{|c|c|}
\hline Nomenclature & \\
\hline$j$ & Index of diesel generators, $\mathrm{j} \in\{1, \ldots, \mathrm{J}\}$ \\
\hline$t$ & Index of hours, $t \in\{1, \ldots, T\}$ \\
\hline$s$ & Index of scenarios, $s \in\{1, \ldots, S\}$ \\
\hline$Z$ & Total costs $(\$)$ \\
\hline$\alpha_{j t s}$ & State of unit $j$ at hour t in scenario $s(0 / 1)$ \\
\hline$\beta_{j t s}$ & $\begin{array}{l}\text { Start-up decision variable of unit } j \text { at hour } t \text { in } \\
\text { scenario } s(0 / 1)\end{array}$ \\
\hline$\gamma_{j t s}$ & $\begin{array}{l}\text { Shut-down decision variable of unit } j \text { at hour } \mathrm{t} \\
\text { in scenario } s(0 / 1)\end{array}$ \\
\hline$\xi_{j t s}$ & $\begin{array}{l}\text { Charge/discharge decision variable of battery } \\
\text { at hour t in scenario } \mathrm{s}(0 / 1)\end{array}$ \\
\hline$P_{j t s}$ & $\begin{array}{l}\text { Power generated by unit } \mathrm{j} \text { at hour } \mathrm{t} \text { in scenario } \\
\mathrm{s}(\mathrm{kW})\end{array}$ \\
\hline$P_{\text {insert }, t s}$ & $\begin{array}{l}\text { Power imported from the upstream grid at } \\
\text { hour } \mathrm{t} \text { in scenario } \mathrm{s}(\mathrm{kW})\end{array}$ \\
\hline$P_{\text {out }, t s}$ & $\begin{array}{l}\text { Power exported to the upstream grid at hour } t \\
\text { in scenario } \mathrm{s}(\mathrm{kW})\end{array}$ \\
\hline$S R_{j t s}$ & $\begin{array}{l}\text { Reserve power provided by unit } \mathrm{j} \text { at hour } \mathrm{t} \text { in } \\
\text { scenario } \mathrm{s}(\mathrm{kW})\end{array}$ \\
\hline$S R_{\text {upstream,ts }}$ & $\begin{array}{l}\text { Reserve power provided by the upstream grid } \\
\text { at hour t in scenario s }(\mathrm{kW})\end{array}$ \\
\hline
\end{tabular}

\begin{tabular}{|c|c|}
\hline$S R_{m g, t s}$ & $\begin{array}{l}\text { Available spinning reserve in the system at } \\
\text { hour t in scenario } \mathrm{s}(\mathrm{kW})\end{array}$ \\
\hline $\begin{array}{l}P_{\text {charg,ts }} \\
/ P_{\text {discharg }, t s}\end{array}$ & $\begin{array}{l}\text { Permitted rate of charge/discharge at hour } \mathrm{t} \\
\text { in scenario } \mathrm{s}(\mathrm{kW})\end{array}$ \\
\hline$S O C_{t s}$ & $\begin{array}{l}\text { Charge state of battery at hour } t \text { in scenario s } \\
(\%)\end{array}$ \\
\hline$\rho_{s}$ & Probability of scenario s \\
\hline$C_{r}$ & Reserve price $(\$ / \mathrm{kWh})$ \\
\hline$C_{\text {upstream }}$ & $\begin{array}{l}\text { Price of power exchange with the upstream } \\
\text { grid at hour } \mathrm{t}(\$ / \mathrm{kWh})\end{array}$ \\
\hline$D_{t s}$ & $\begin{array}{l}\text { Forecasted demand at hour t in scenario s } \\
(\mathrm{kW})\end{array}$ \\
\hline$W_{t s}$ & $\begin{array}{l}\text { Forecasted wind power generation at hour } \mathrm{t} \text { in } \\
\text { scenario } \mathrm{s}(\mathrm{kW})\end{array}$ \\
\hline$P V_{t s}$ & $\begin{array}{l}\text { Forecasted solar power generation at hour } \mathrm{t} \text { in } \\
\text { scenario } \mathrm{s}(\mathrm{kW})\end{array}$ \\
\hline$S R_{t s}$ & $\begin{array}{l}\text { System's spinning reserve requirement at } \\
\text { hour t in scenario s }(\mathrm{kW})\end{array}$ \\
\hline$P_{j}^{\min }$ & Minimum power generation of unit $\mathrm{j}(\mathrm{kW})$ \\
\hline$P_{j}^{\max }$ & Maximum power generation of unit $\mathrm{j}(\mathrm{kW})$ \\
\hline $\mathrm{P}_{\text {upstream }}^{\max }$ & $\begin{array}{l}\text { Maximum exchanging power between } \\
\text { upstream grid and micro-grid(kW) }\end{array}$ \\
\hline$\alpha_{\mathrm{D}}$ & Load forecasting error factor \\
\hline$\alpha_{W}$ & Wind power forecasting error factor \\
\hline$\alpha_{\mathrm{PV}}$ & Solar power forecasting error factor \\
\hline $\mathrm{STC}_{\mathrm{j}}$ & Turn on cost of unit j (\$) \\
\hline $\mathrm{SDC}_{\mathrm{j}}$ & Shut-down cost of unit j (\$) \\
\hline $\mathrm{RR}_{\mathrm{j}}$ & Ramp rate of unit $\mathrm{j}(\mathrm{kW} / \mathrm{hr})$ \\
\hline$M U T_{j}$ & Minimum up time of unit $\mathrm{j}(\mathrm{hr})$ \\
\hline$M D T_{j}$ & Minimum down time of unit $\mathrm{j}(\mathrm{hr})$ \\
\hline$\eta_{\text {charge }} / \eta_{\text {discharge }}$ & Charge/discharge efficiency of the battery \\
\hline $\mathrm{P}_{\text {charge }}^{\max } / \mathrm{P}_{\text {discharge }}^{\max }$ & $\begin{array}{l}\text { Maximum rate of charge/discharge during } \\
\text { each time interval }\end{array}$ \\
\hline battery $_{\max }$ & Maximum capacity of battery \\
\hline $\mathrm{SOC}_{\max } / \mathrm{SOC}_{\min }$ & $\begin{array}{l}\text { Maximum/minimum charge status of the } \\
\text { battery }\end{array}$ \\
\hline
\end{tabular}

\section{References}

Abedi S., Alimardani A., Gharehpetian G.B., Riahy G.H., Hosseinian S.H. (2012) A comprehensive method for optimal power management and design of hybrid RES-based autonomous energy systems. Renewable and Sustainable Energy Reviews, 16, 1577- 1587.

Alabedin A. Z. (2012) Generation Scheduling in Microgrids under Uncertainties in Power Generation, MAS Dissertation, University of Waterloo.

Alharbi, W., Raahemifar, K., (2015) Probabilistic coordination of microgrid energy resources operation considering uncertainties. Electric Power Systems Research, 128, 1-10.

Allali K., Azzag E., Labar H. (2015) Techno-economic Analysis of a Wind-Diesel Hybrid Power System in the South Algeria. International Journal of Renewable Energy Development, 4(2),137142.

Bahramara S., Parsa Moghaddam M., Haghifam M.R. (2015) Modelling hierarchical decision making framework for operation of active distribution grids. IET Generation, Transmission \& Distribution, 9(16), 2555-2564.

Baziar A.A, Kavousi-Fard A. (2013) Considering uncertainty in the optimal energy management of renewable micro-grids including storage devices. Renewable Energy, 59,158-166.

Chen C., Duan S., Cai T., Liu B., Hu G. (2011) Smart energy management system for optimal microgrid economic operation. IET Renewable Power Generation, 5 (3), 258-267.

Chen Y. H., Lu S. Y., Chang Y. R., Lee T. T., Hu M. C., (2012) Economic analysis and optimal energy management models for microgrid systems: A case study in Taiwan. Applied Energy.

Dagdougui H., Minciardi R., Ouammi A., Robba M., Sacile R. (2012) Modeling and optimization of a hybrid system for the energy 
Citation: Jasemi, M., Adabi, F., Mozafari, B., Salahi, S. (2016). Optimal Operation of Micro-grids Considering the Uncertainties of Demand and Renewable Energy Resources Generation. Int. Journal of Renewable Energy Development, 5(3), 233-248, doi: 10.14710/ijred.5.3.233-248

$\mathrm{P}$ a g e $\mid 248$

supply of a "Green" building. Energy Conversion and Management, 64, 351-363.

Dai, R., Mesbahi, M., (2013) Optimal power generation and load management for off-grid hybrid power systems with renewable sources via mixed-integer programming. Energy Conversion and Management, 73, 234-244.

Elsied, M., Oukaour, A., Gualous, H., Lo Brutto, O. A., (2016) Optimal economic and environment operation of micro-grid power systems. Energy Conversion and Management, 122, 182-194.

Hatziargyriou N., Asano H., Iravani R., Marnay C. (2007) Microgrids. IEEE Power and Energy Magazine, 5 (4), 78-94.

Kanchev H., Lu D., Colas F., Lazarov V., Francois B. (2011) Energy Management and Operational Planning of a Microgrid With a PVBased Active Generator for Smart Grid Applications. IEEE Transactions on Industrial Electronics, 58 (10):4583-4592.

Lagorse J., Paire D., Miraoui A. (2010). A multi-agent system for energy management of distributed power sources. Renewable Energy, 35, 174-182,

Logenthiran T., Srinivasan D. (2009) Short term generation scheduling of a Microgrid. TENCON 2009 - 2009 IEEE Region 10 Conference, pp.1-6.
Mohamed A., Mohammed 0. (2013) Real-time energy management scheme for hybrid renewable energy systems in smart grid applications. Electric Power Systems Research, 96, 133-143.

Motevasel M., Seifi A., Niknam T. (2012) Multi-objective energy management of CHP (combined heat and power) -based microgrid. Energy, 1-14.

Niknam T., Golestaneh F., Malekpour A. (2012) Probabilistic energy and operation management of a microgrid containing wind/photovoltaic/fuel cell generation and energy storage devices based on point estimate method and self-adaptive gravitational search algorithm. Energy, 43, 427-437.

Niknam, T., Azizipanah-Abarghooee, R., Narimani, M. R., (2012) An efficient scenario-based stochastic programming framework for multi-objective optimal micro-grid operation. Applied Energy, 99, 455-470.

Peik-Herfeh M., Seifi H., Sheikh-El-Eslami M.K. (2013) Decision making of a virtual power plant under uncertainties for bidding in a dayahead market using point estimate method. Electrical Power and Energy Systems, 44, 88-98.

Salahi, S., and Bahramara, S. (2016) Modeling Operation Problem of Micro-grids Considering Economical, Technical and Environmental issues as Mixed-Integer Non-Linear Programming. International Journal of Renewable Energy Development, 5 (2),139-149. 